\title{
Rare injury of the foot: Os trigonum fracture: A case report
}

\author{
Bülent Yücel(D, Savaş Baytar (D), Adem Aydın (1) \\ Department of Orthopedics and Traumatology, Acıbadem Bahçeşehir Medical Center, Istanbul, Turkey
}

Os trigonum is located at the posterolateral of talus and rarely it can be bipartite. Os trigonum is connected to the talar process by fibrocartilage structure. It is seen as the process of the lateral tubercle of the posterior talar process when fusion happens, also known as "Stieda process". ${ }^{[1-5]}$

Fractures of this small accessory bone are rarely reported in the literature. Only eight cases reported in the literature were identified..$^{[1,6-11]}$ Most of the cases in the literature occurred with falling from a stair, falling from a height and during sports. Injury that causes the os trigonum fracture usually happens by the overloading of the ankle in acute hyperplantar flexion. ${ }^{[9]}$ Dancers and athletes who participate in kicking sports are particularly susceptible to these injuries because their feet are in a forced plantar flexed position. ${ }^{[12]} X$-ray, computed tomography (CT) and magnetic resonance imaging (MRI) scans can be used in the diagnosis of os trigonum fractures and accompanying injuries. ${ }^{[3,6,7]}$ Generally, os trigonum fractures are treated with short leg cast for six weeks of duration. ${ }^{[1]}$ These injuries are often confused with Achilles tendon

Received: February 28, 2020

Accepted: May 27, 2020

Published online: September 11, 2020

Correspondence: Bülent Yücel, MD. Acıbadem Bahçeşehir Tıp Merkezi Ortopedi ve Travmatoloji Bölümü, 34550 Başakşehir, İstanbul, Türkiye.

E-mail:dr2000tr@yahoo.com

Doi: $10.5606 /$ ehc. 2020.74530

Citation: Yücel B, Baytar B, Aydın A. Rare injury of the foot: Os trigonum fracture: A casereport. JtDis RelatSurg 2020;31(3):626-629.

(92020 All right reserved by the Turkish Joint Diseases Foundation

This is an open access article under the terms of the Creative Commons Attribution-NonCommercial License, which permits use, distribution and reproduction in any medium, provided the original work is properly cited and is not used for commercial purposes (http://creativecommons.org/licenses/by-nc/4.0/).

\section{ABSTRACT}

Os trigonum fractures are seen rarely. Our patient was a 16-year-old male patient who applied to our emergency service with right ankle pain due to acute hyperplantar flexion while playing football. There was a swelling on the right ankle and he had difficulty in walking. Os trigonum fracture was detected at lateral X-ray of the right ankle. No additional injury was detected with computed tomography and magnetic resonance imaging (MRI). Patient was treated conservatively. A short leg cast was applied. Cast was removed after six weeks and range of motion exercises were started. Union of fracture was seen on X-ray at six weeks from injury. Conservative treatment is thought to be a good option in these fractures. Computed tomography and MRI are important in the differential diagnosis and evaluation of additional injuries in this type of fracture.

Keywords: Accessory bone, foot injuries, os trigonum fracture.

and flexor hallucis longus injuries because of the proximity of the os trigonum to these structures. Missed os trigonum fractures may result in persistent pain and posterior-ankle impingement syndrome. Surgical excision can be performed when there is a symptomatic nonunion and impingement syndrome resistant to conservative management. ${ }^{[1,6,12]}$

In this article, we report a case with acute fracture of os trigonum due to a football injury that is seen rarely and should be kept in mind in the differential diagnosis of ankle injuries. ${ }^{[13]}$

\section{CASE REPORT}

A 16-year-old male patient applied to our emergency service with right ankle pain following a football injury. His history revealed forced acute hyperplantar flexion. There was a mild swelling at the posterolateral side of right ankle and he had difficulty in walking. Posterior ankle and back of the lateral malleoli were painful by palpation. Os trigonum fracture was detected at lateral X-ray of the 


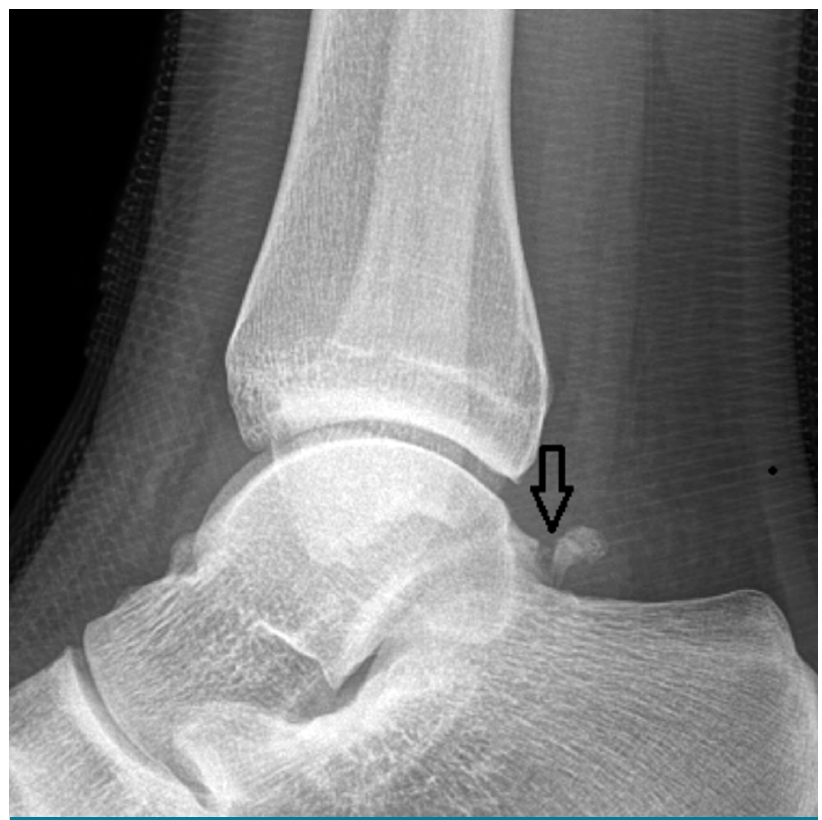

FIGURE 1. Lateral X-ray of right ankle after injury. Os trigonum fracture is seen (arrow).

right ankle (Figure 1). Fracture was seen more clearly when actual X-rays were compared to the patient's older X-rays which were taken when he presented to our clinic because of ankle sprain two months ago (Figure 2). The patient had been treated with a short leg splint, since no fracture was detected. The splint was removed one week later and joint range of motion and strengthening exercises were started. After three weeks, the patient was fully recovered. A written informed consent was obtained from the legal guardian of the patient.

Os trigonum fracture and surrounding edema were detected by CT and MRI (Figure 3). There was no

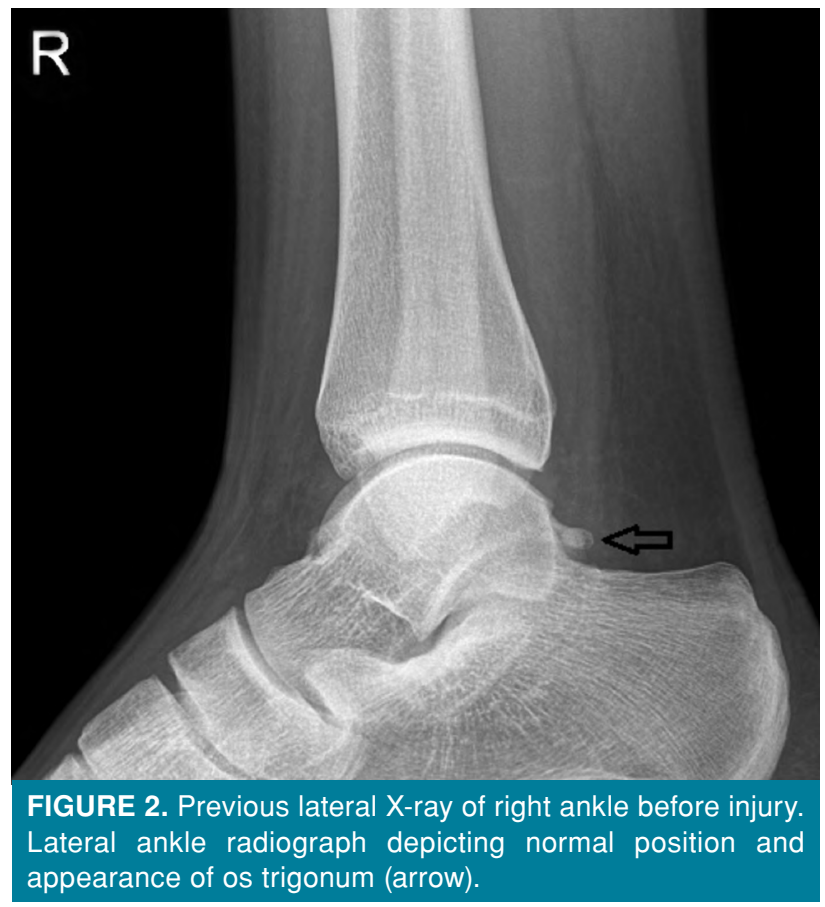

additional injury. Patient was treated conservatively. A non-weight bearing short leg cast was applied. Union of fracture was seen on sixth week X-ray (Figure 4). Cast was removed after six weeks. Joint range of motion and strengthening exercises were started. The patient was allowed full weight bearing when the cast was removed. Painless and full range of motion was obtained four weeks after cast removal. The patient was followed-up for a total of three months. Nonunion, chronic pain or posterior ankle impingement syndrome was not detected in the patient after the treatment. The patient returned to sports activities without any complaints.
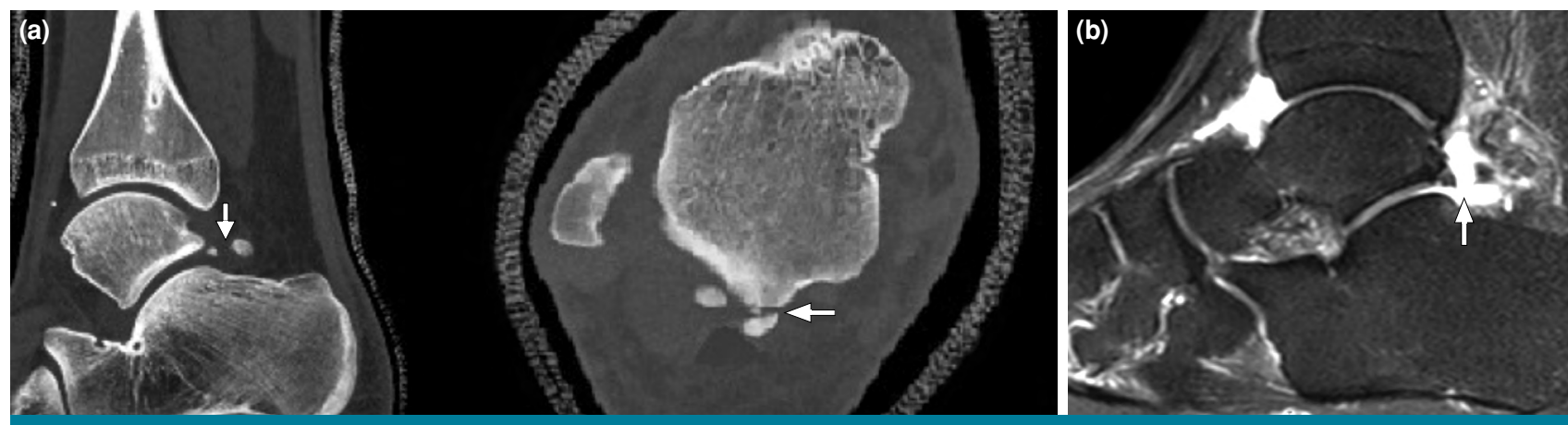

FIGURE 3. (a) Sagittal and axial computed tomography scans of ankle showed a fracture of os trigonum (arrow). No additional injury was detected. (b) Magnetic resonance imaging of right ankle. Os trigonum fracture and surrounding edema are seen (arrow). No additional injury was detected. 


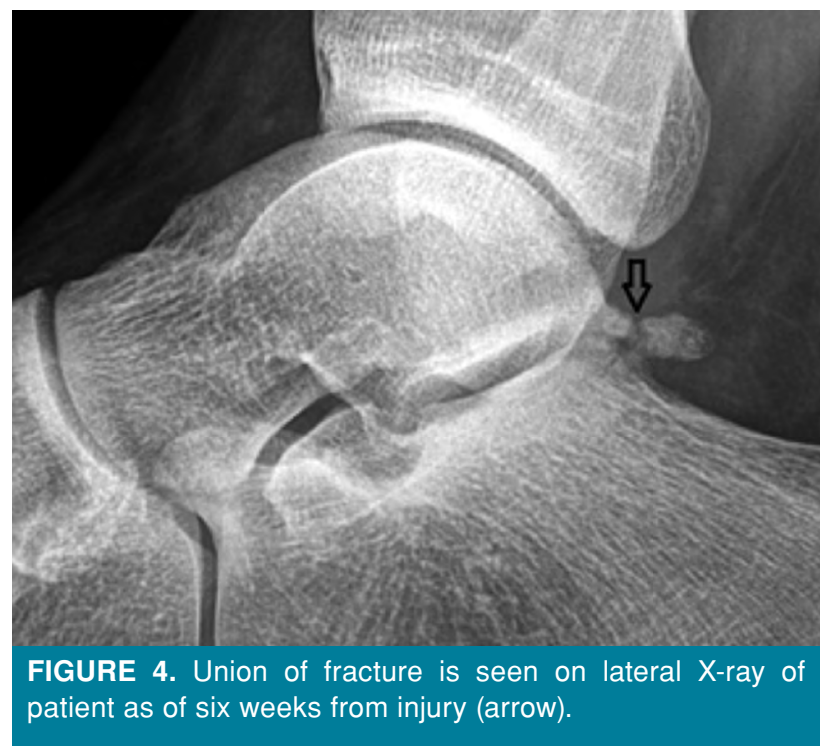

\section{DISCUSSION}

The os trigonum is the most common accessory bone of the foot located posterolateral to the talus. ${ }^{[9]}$

Os trigonum fracture is a rare entity which may be misdiagnosed as a fracture of the posterior process of the talus. ${ }^{[9]}$ Radiography alone may not be sufficient for the diagnosis of os trigonum fractures. Computed tomography is useful to differentiate os trigonum fractures and bipartite os trigonum. Computed tomography is more sensitive than radiographs in the detection and differentiation of an os trigonum fracture from a fracture of the posterior talar process. ${ }^{[1,3,11,14]}$ Os trigonum fracture was detected by lateral X-ray of ankle in the presented case. Additional injuries were evaluated with $\mathrm{CT}$ and MRI examination. Os trigonum fracture and surrounding edema were detected in CT and MRI imaging. Kose et al. ${ }^{[9]}$ reported that direct radiographs showed the presence of an os trigonum fracture without osseous pathology.

Typical accessory bones with solid cortex and smooth margins are seen in bipartite os trigonum. Computed tomography can be used in differential diagnosis of posteromedial tubercle fractures of talus, too. ${ }^{[8]}$ Sekhon et al. ${ }^{[1]]}$ reported that a missed diagnosis may result in complications such as nonunion, chronic pain and posterior-ankle impingement syndrome. Kocaoğlu et al. ${ }^{[10]}$ reported that os trigonum fracture may result in loose body. Magnetic resonance imaging is not recommended routinely but can be useful to determine the concomitant injuries like Achilles tendon injuries, flexor hallucis longus injuries or bone marrow edema. ${ }^{[3,6,7]}$
Mechanism of injury was reported as acute hyperplantar flexion of the foot in presented case. Reissing et al. ${ }^{[6]}$ reported that dancers and athletes who participate in kicking sports are particularly susceptible to these injuries because their feet are in a forced plantar flexed position. Kose et al. ${ }^{[9]}$ also reported that hyperplantar flexion of the ankle is the mechanism of injury, compressing the os trigonum between the posterior malleolus of the tibia and the tuber calcaneus.

We treated the patient with non-weight bearing short leg cast for six weeks. Yan et al..[1] reported a positive result with six-week plaster treatment of os trigonum fracture. Majeed et al. ${ }^{[15]}$ reported that nondisplaced fractures could be managed in a plaster cast for six to eight weeks. Reissing et al. ${ }^{[6]}$ reported that conservative management consisting of activity modification, nonsteroidal anti-inflammatory drugs, ice, immobilization and rest should be done firstly. Kose et al. ${ }^{[9]}$ reported that conservative treatment is usually successful although nonunion has been reported. In addition to conservative treatment, if the patient's complaints do not regress within three-six months, os trigonum excision can be performed with open or arthroscopic surgery ${ }^{[6,16]}$ Several reports include that a missed diagnosis may result in complications such as nonunion, chronic pain and posterior-ankle impingement syndrome, necessitating surgical excision of the un-united fragment. ${ }^{[11,12,16]}$

In conclusion, we have highlighted the evaluation of this type of injuries and the importance of differentiating the os trigonum fractures and posterior talar process fractures with this case. Computed tomography and MRI are important in the differential diagnosis and evaluation of additional injuries in these fractures. Conservative treatment can be a good choice in os trigonum fracture. With an appropriate diagnosis, conservative treatment is usually successful, enabling patients to achieve normal function.

\section{Declaration of conflicting interests}

The authors declared no conflicts of interest with respect to the authorship and/or publication of this article.

\section{Funding}

The authors received no financial support for the research and/or authorship of this article.

\section{REFERENCES}

1. Yan YY, Mehta KV, Tan TJ. Fracture of the os trigonum: A report of two cases and review of the literature. Foot Ankle Surg 2016;22:e21-e4. 
2. Keles-Celik N, Kose O, Sekerci R, Aytac G, Turan A, Güler F. Accessory Ossicles of the Foot and Ankle: Disorders and a Review of the Literature. Cureus 2017;9:e1881.

3. Guo S, Yan YY, Lee SSY, Tan TJ. Accessory ossicles of the foot-an imaging conundrum. Emerg Radiol 2019;26:465-78.

4. Özer M, Yıldırım A. Evaluation of the Prevalence of Os Trigonum and Talus Osteochondral Lesions in Ankle Magnetic Resonance Imaging of Patients With Ankle Impingement Syndrome. J Foot Ankle Surg 2019;58:273-7.

5. Russell TG, Byerly DW. Talus Fracture. 2019 Jun 8. StatPearls [Internet]. Treasure Island (FL): StatPearls Publishing; 2019 Jan-. Available at: http://www.ncbi.nlm.nih.gov/books/ NBK539687/

6. Reissig J, Bitterman A, Lee S. Common Foot and Ankle Injuries: What Not to Miss and How Best to Manage. J Am Osteopath Assoc 2017;117:98-104.

7. Kao HK, Gamble JG. Painful Ununited Fracture of the Posterior Process of the Talus in an Adolescent Dancer: A Case Report. JBJS Case Connect 2014;4:e92.

8. Albert P, Patel J, Katz JI, Loria F, Parnell J, Brenner M. Magnetic resonance imaging, computed tomography, and radiographic correlation of nonunion of the posteromedial tubercle of the talus: a case report. J Foot Ankle Surg 2014;53:787-90.
9. Kose O, Okan AN, Durakbasa MO, Emrem K, Islam NC. Fracture of the os trigonum: a case report. J Orthop Surg (Hong Kong) 2006;14:354-6.

10. Kocaoglu B, Akgun U, Nuran R, Karahan M. Dislocation of os trigonum presenting as a loose body in the ankle. J Foot Ankle Surg 2009;48:215-9.

11. Sekhon R, Wong D. Os Trigonum Fracture: An unusual injury. 2017 Rehabilitation Medicine Society of Australia and New Zealand 2nd Annual Scientific Meeting. September 17-20, 2017, New Zealand, Australian; 2017.

12. Park $\mathrm{CH}$, Park $\mathrm{KH}$. Fracture of the Posterior Process of the Talus With Concomitant Subtalar Dislocation. J Foot Ankle Surg 2016;55:193-7.

13. Atik OŞ. Which articles do we prefer to publish? Eklem Hastalik Cerrahisi 2018;29:1.

14. Ebraheim NA, Skie MC, Podeszwa DA, Jackson WT. Evaluation of process fractures of the talus using computed tomography. J Orthop Trauma 1994;8:332-7.

15. Majeed $\mathrm{H}$, McBride DJ. Talar process fractures: An overview and update of the literature. EFORT Open Rev 2018;3:85-92.

16. Carreira DS, Vora AM, Hearne KL, Kozy J. Outcome of Arthroscopic Treatment of Posterior Impingement of the Ankle. Foot Ankle Int 2016;37:394-400. 